\title{
Extramedullary Involvement
}

National Cancer Institute

\section{Source}

National Cancer Institute. Extramedullary Involvement. NCI Thesaurus. Code C122601.

A finding indicating the involvement of sites other than the bone marrow by a

hematopoietic neoplasm. 